\title{
Stereotactic Radiosurgery for Acoustic Neuroma: A Canadian Perspective
}

\author{
Ian B. Ross and Charles H. Tator
}

\begin{abstract}
Stereotactically delivered radiation is now an accepted treatment for patients with acoustic neuroma. In some cases, patient preference may be the reason for its selection, while in others neurosurgeons may select it for patients who are elderly or have significant risk factors for conventional surgery. The majority of patients with acoustic neuroma treatment with stereotactic radiosurgery have been treated with the Gamma Knife, with follow ups of over 25 years in some instances. Other radiosurgical modalities utilizing the linear accelerator have been developed and appear promising, but there is no long-term follow up. Canada does not possess a Gamma Knife facility, and its government-funded hospital and medical insurance agencies have made it difficult for patients to obtain reimbursement for Gamma Knife treatments in other countries. We review the literature to date on the various forms of radiation treatment for acoustic neuroma and discuss the current issues facing physicians and patients in Canada who wish to obtain their treatment of choice.
\end{abstract}

\begin{abstract}
RÉSUMÉ: La radiochirurgie stéréotaxique du neurinome acoustique - Une perspective canadienne. L'irradiation stéréotaxique est maintenant un traitement reconnu chez les patients qui ont un neurinome acoustique. Dans certains cas, la préférence du patient peut être la raison de ce choix, alors dans d'autres cas le neurochirurgien peut choisir ce traitement pour les patients qui sont âgés ou chez qui la chirurgie conventionnelle présente des facteurs de risque importants. La majorité des patients qui sont traités par radiochirurgie stéréotaxique pour un neurinome acoustique ont été traités au moyen du scalpel gamma, avec un suivi de plus de 25 ans dans certains cas. D'autres modalités radiochirurgicales utilisant l'accélérateur linéaire ont été développées et semblent prometteuses, mais un suivi à long terme n'est pas disponible. Le Canada n'a pas d'institution qui possède de scalpel gamma et le fait que ses hôpitaux sont subventionnés par des fonds publiques et les limites établies par les compagnies d'assurance médicale font qu'il est difficile pour les patients d'obtenir un remboursement pour le traitement par le scalpel gamma dans d'autres pays. Nous revoyons la littérature sur les différentes formes d'irradiation pour le traitement du neurinome acoustique et nous discutons des problèmes auxquels font face au Canada les médecins et les patients qui désirent obtenir le traitement de leur choix.
\end{abstract}

Can. J. Neurol. Sci. 1998; 25: 310-314

The concept of stereotactic radiosurgery was developed in the early 1950 s by Lars Leksell, ${ }^{1}$ in Stockholm, who first treated a patient with an acoustic neuroma with this modality in 1969.2 Recently, there has been wider application of stereotactic radiosurgery for the treatment of a variety of brain disorders. ${ }^{3}$ The technique, originally developed for the destruction of thalamic nuclei in the treatment of movement disorders, has also been used for the treatment of arteriovenous malformations, pituitary adenomas, gliomas, brain metastases, meningiomas and other intracranial tumors. Acoustic neuromas represent one of the most frequently treated lesions with the Gamma Knife. For acoustic neuromas, there is a controversy over whether stereotactic radiosurgery delivered by the Gamma Knife, manufactured by Elekta Instruments in Stockholm, Sweden, is superior to that delivered by the linear accelerators (LINAC) which are manufactured by several companies.

This issue is currently of great importance in Canada. While several LINAC radiosurgery units are in operation in Canada, there is no Gamma Knife facility in the country. Reimbursement to the patient for medical services rendered outside of Canada is generally reserved for emergencies and those treatments that are not available in the country. Provincial government insurance agencies, for reasons of cost, mandate that physicians and patients utilize locally available LINAC systems as opposed to out-of-country Gamma Knife units. They argue that "equivalent" treatment is provided by the LINAC. By law, government agencies are legally bound to provide "equivalent" treatment in Canada or to reimburse patients who obtain medical treatment out of the country when such treatment is not available in Canada. Several provincial governments in Canada have been asked to purchase a Gamma Knife by various patient groups, including the Acoustic Neuroma Association of Canada, hospitals and physicians, but the governments have refused. Many patients, however, have received Gamma Knife treatments for acoustic neuroma and other conditions in the United States and elsewhere.

From the Section of Neurosurgery (I.B.R.); University of Manitoba, Winnipeg; and the Division of Neurosurgery (C.H.T.) University of Toronto, Toronto

RECEIVED MARCH 16, 1998. ACCEPTED IN FINAL FORM JUNE 23, 1998

Reprint requests to: Ian B. Ross, M.D. Section of Neurosurgery, University of Manitoba, Z3017-409 Tache Ave., Winnipeg, MB, Canada R2H 2A6 
At times, courts have ordered the provincial governments to pay for these treatments and have ruled that the LINAC is not equivalent.

\section{Physical Factors}

Both the Gamma Knife and the LINAC deliver an identical form of energy, photons, to localized areas with rapid fall off of radiation in the surrounding normal structures. The Gamma Knife uses 201 distinct cobalt-60 sources, with entry ports that largely surround the patient's head, to deliver photons to the target. Neither the radiation source nor the patient move during treatment. The size of the collimators at the entry ports determines the volume of tissue irradiated with the Gamma Knife. The calculation and delivery of radiation to irregularly shaped tumors, which requires multiple isocentres (ie. targets), is relatively simple. In contrast, the radiosurgical LINAC systems generally use the standard LINAC machines found in all up-to-date radiation oncology departments. These machines are primarily used for malignant tumors in non-neural organs and tissues. A high radiation dose at the isocentre, with rapid fall off at the periphery, is achieved by rotation of the LINAC around the patient's head, through different arcs. With some LINAC systems, the patient also rotates. The delivery to irregular targets with some LINAC radiosurgical units requires more complicated mathematics, and is therefore less often done. With both systems the dose to the skin and surrounding brain tissue is reduced by using multiple entry/exit points for the radiation, thereby minimizing the parallel port effect, while maximizing the energy at the isocentre. The greatest controversy, in Canada, exists in the area of the treatment of acoustic neuroma. Because of the proximity of important cranial nerves, and the brain stem, accurate targeting is essential. Also, because an acoustic neuroma almost always has a tail that extends into the internal auditory canal and frequently has an irregular, non-spherical shape in the cerebellopontine angle, the ability to conform the radiation to an irregular target is important. Significant advantages of Gamma Knife over LINAC for irregular targets have recently been reported. ${ }^{4}$

\section{Clinical Studies}

Results from major published series of acoustic neuromas treated with stereotactically delivered radiation are summarized in the Table. The literature on the Gamma Knife treatment for acoustic neuroma is substantial. An early experience with 14 patients from the original Gamma Knife unit at the Karolinska Institute in Stockholm was published by Noren in 1983,5 and then a presentation of 254 cases was made in 1993 by the same group. ${ }^{6}$ Some of the patients included in this series dated from the pre-CT era, and the radiation doses administered to the early cases were greater than what is now standard. The most recent communication by Noren reports a $93 \%$ growth control rate with moderate trigeminal $(8 \%)$ and facial $(14 \%)$ nerve dysfunction in the most recently analyzed cohort from $1989-1990 .^{7}$ The group in Pittsburgh has also had a large experience with the Gamma Knife and acoustic neuromas. A study in 1995 indicated that stereotactic radiosurgery using the Gamma Knife is an effective treatment for unilateral acoustic neuromas less than $3 \mathrm{~cm}$ in diameter, and is less costly than microsurgical excision. ${ }^{8}$
The Pittsburgh group now report a tumor control rate of $94 \%$ in patients recently treated. ${ }^{9}$ The combined experience of these leading Gamma Knife centres is currently over 1000 patients. The Gamma Knife unit at the Mayo Clinic has reported a tumor control rate of $100 \%$, but with a higher than average cranial neuropathy rate. ${ }^{10}$ They discount this by alluding to a larger than average tumor size and also to very close follow up of their patients. The Mayo Clinic unit is relatively new, and the faster radiation delivery rates associated with new cobalt 60 sources have been associated with higher rates of cranial neuropathy.? Also, there is likely a "learning curve" of acoustic neuroma radiosurgery, and the higher complication rate in this series may simply reflect the experience of the surgeon. ${ }^{11}$ More than 5000 patients with acoustic neuroma had been treated with the Gamma Knife by the end of $1995 .{ }^{9}$ There has not been a single instance of radiation-induced tumor, neither benign nor malignant.

Experience with LINAC based radiosurgical treatment of acoustic neuromas is much smaller, and more recent, although it has been growing. The group at the University of Florida has reported their results on 56 patients with acoustic neuroma who underwent LINAC treatment. ${ }^{12}$ This is an update of an earlier report of 32 patients. ${ }^{13}$ This group had a good tumor control rate, with a cranial neuropathy rate of $20 \%$, which compares favorably to the Karolinska and Pittsburgh groups. The next largest published series included 23 patients who had 24 acoustic neuromas and were radiated stereotactically with a LINAC and followed for more than two years with good tumor control. ${ }^{14}$ This last group received a higher dose of radiation, with a mean of 30 Gy at periphery and the results seem anomalous since other groups had a higher cranial neuropathy rate, and a lower incidence of hearing preservation, with similarly large doses of radiation. A problem in evaluating the LINAC programs is the marked variation in the methodology of targeting and delivering the radiation, whereas the Gamma Knife units are very similar, being manufactured by a single supplier. Thus, it is not practical to pool the LINAC data and each LINAC radiosurgery unit must be evaluated separately. Based on the literature to date, only the University of Florida group has comparable results with respect to toxicity and tumor control to the Gamma Knife units, but the LINAC follow-up is much shorter.

In general, it has been difficult for patients and referring neurosurgeons to compare results because patient follow-up has been for varying lengths of time in the different series, and when comparing complications such as cranial neuropathies, reporting has varied. For example, facial tingling was not considered to represent a complication involving the trigeminal nerve by some investigators, and similarly some authors did not judge worsening of a pre-existing cranial neuropathy as a complication. It must be noted, however, that the vast majority of acoustic neuroma patients treated by radiosurgery to date have been with the Gamma Knife and that the longest follow ups, some over 25 years, have been with this modality.

\section{The IsSue of Fractionation}

A new form of stereotactically targeted radiation therapy, fractionated stereotactic radiotherapy, for acoustic neuroma is now available. Only LINAC units have been used for fractionation to date, with the radiation being delivered in small doses (1.8-6.1 Gy) over multiple fractions (4-30). Preliminary results 
Table 1: Summary of Results of Stereotactically Delivered Radiation Treatments for Acoustic Schwannomas.

\begin{tabular}{|c|c|c|c|c|c|c|c|}
\hline $\begin{array}{l}\text { Radiation } \\
\text { Delivery } \\
\text { System }\end{array}$ & $\begin{array}{l}\text { Author/ } \\
\text { Institution }\end{array}$ & $\mathrm{n}$ & $\begin{array}{l}\text { Radiation } \\
\text { *Dose }\end{array}$ & $\begin{array}{c}\text { Tumor } \\
\text { Control } \\
+\end{array}$ & $\begin{array}{l}\text { CN Palsy } \\
\text { V VII }\end{array}$ & $\begin{array}{c}\text { Preservation } \\
\text { of useful } \\
\text { Hearing } \\
+\end{array}$ & Follow-Up \\
\hline Gamma Knife & $\begin{array}{l}\text { Noren }, \\
1998(7) \\
\text { Karolinska I. } \\
\text { Brown U. }\end{array}$ & 71 & $8-20 \mathrm{~Gy}$ & $93 \%$ & $8 \% \quad 14 \%$ & $60 \%$ & $0.8-5.6 \mathrm{yr}$ \\
\hline Gamma Knife & $\begin{array}{l}\text { Kondziolka et } \\
\text { al, 1997(9) } \\
\text { U. Of } \\
\text { Pittsburgh }\end{array}$ & 83 & $16 \mathrm{~Gy}$ & $94 \%$ & $8 \% \quad 11 \%$ & N/A & mean $36 \mathrm{mo}$ \\
\hline Gamma Knife & $\begin{array}{l}\text { Foote et al, } \\
1995(10) \\
\text { Mayo Clinic }\end{array}$ & 36 & $\begin{array}{c}16-20 \mathrm{~Gy} \\
(\text { mean=15.5) }\end{array}$ & $100 \%$ & $67 \% \quad 59 \%$ & $42 \%$ & $3 \mathrm{mo}-2 \mathrm{yr}$ \\
\hline LINAC & $\begin{array}{l}\text { Mendenhall } \\
\text { et al, } \\
\text { 1996(12) } \\
\text { U. of Florida }\end{array}$ & 56 & $\begin{array}{l}10-22.5 \mathrm{~Gy} \\
(69.6 \%=12.5 \\
15 \mathrm{~Gy})\end{array}$ & $98 \%$ & $\begin{array}{c}\text { combined } \\
21 \%\end{array}$ & N/A & $1-5 \mathrm{yr}$ \\
\hline LINAC & $\begin{array}{l}\text { Valentino \& } \\
\text { Raimondi, } \\
\text { 1995(14) } \\
\text { Clinica } \\
\text { Flaminia, } \\
\text { Rome and } \\
\text { North- } \\
\text { western U. }\end{array}$ & 24 & $\begin{array}{l}12-45 \mathrm{~Gy} \\
\text { (median= } \\
30 \mathrm{~Gy})\end{array}$ & $85 \%$ & $4 \% \quad 7 \%$ & $100 \%$ & $2-8 y r$ \\
\hline $\begin{array}{l}\text { Fractionated } \\
\text { Radiotherapy }\end{array}$ & $\begin{array}{l}\text { Andrews et } \\
\text { al, 1995(15) } \\
\text { Thomas } \\
\text { Jefferson U. }\end{array}$ & 27 & $\begin{array}{l}24-51 \mathrm{~Gy} \\
(5-27 \\
\text { fractions) }\end{array}$ & $100 \%$ & $0 \% \quad 13 \%$ & $71 \%$ & $3-27 \mathrm{mo}$ \\
\hline $\begin{array}{l}\text { Fractionated } \\
\text { Radiotherapy }\end{array}$ & $\begin{array}{l}\text { Varlotto et al, } \\
\text { 1996(16) } \\
\text { Harvard U. }\end{array}$ & 12 & $\begin{array}{c}254 \mathrm{~Gy} \\
\text { (over } 27-30 \\
\text { fractions) }\end{array}$ & $100 \%$ & $\stackrel{\sim}{\text { combined } 8 \%}$ & $100 \%$ & $16-44 \mathrm{mo}$ \\
\hline
\end{tabular}

* dose at tumor periphery for gamma knife and LINAC, or total dose of radiation for fractionated radiotherapy

+ percent of tumors showing no further growth or shrinkage - follow up periods very variable

+ variable follow up

have been published by two groups. The numbers in these series are 26 patients and 12 patients, respectively, ${ }^{15,16}$ and the followup has been very short. The reports indicate that cranial neuropathies, specifically $\mathrm{V}$ and VII, may be less frequent with fractionated stereotactic radiotherapy while tumor control remains excellent. The evolving trend with this treatment has been towards smaller doses $(1.8 \mathrm{~Gy})$ delivered over many daily fractions (27-30). This is based on biological principles developed by radiotherapists treating malignancies in neural and nonneural tissues.

While it has been stated that fractionation may have a biological advantage over single dose radiation for acoustic neuroma, ${ }^{15}$ such an advantage for benign lesions has never been established. Benefit from deceased toxicity to adjacent central and peripheral nervous system structures seems to be the major advantage here, and indeed the development of this modality with hyperfractionation has been encouraged by problems with single dose or hypofractionated treatments. ${ }^{17}$ Perhaps fractionation will have a role in acoustic neuromas in NF2 patients in which the cochlear nerve fibres may be present within the tumor rather than adjacent to the tumor. One concern with fractionation is that the radiation delivery to the target may not be as accurate because the stereotactic device is not fixed to the skull. There is very little information available about the consistency of such devices. Thus, the results of fractionated radiotherapy for acoustic neuroma to date derive from small numbers of patients with very short follow-up.

\section{Cost}

The Gamma Knife is considerably more expensive than the LINAC radiosurgery systems currently on the market. It has recently been estimated that the annual cost for a Gamma Knife, amortised over 10 years, is CDN $\$ 490,000$, whereas that for a 
LINAC system is CDN $\$ 185,000 .{ }^{18}$ As most cancer treatment centres in Canada already have LINAC machines that can be converted for radiosurgery, significant further savings can be realized. Out of country Gamma Knife treatment charges range from CDN $\$ 20,000$ to $\$ 35,000$.

\section{Radiosurgery In CANADA}

LINAC based stereotactic radiosurgery in Canada was first developed at McGill University and has been available for 11 years. The University of Toronto group at Sunnybrook Health Sciences Centre has recently published its results for arteriovenous malformation treatment, ${ }^{19}$ and the McGill University group has published extensively on its experiences, as well. However, there have been no published results on the effect of LINAC radiosurgery on acoustic neuromas from any Canadian centre, though the Sunnybrook group has given a verbal report at a national meeting. ${ }^{20}$ Their results in a small number of patients appear promising. The Ontario Cancer Institute/Princess Margaret Hospital in Toronto, a leading cancer treatment and research centre, has recently indicated a preference for stereotactic fractionated radiotherapy over single dose radiosurgery for acoustic tumors and has instituted a protocol.

For many years the Acoustic Neuroma Association of Cana$\mathrm{da}$, which has several neurosurgeons on its Medical Advisory Board, has advocated that patients with acoustic neuromas who are not surgical candidates by patient choice or physician recommendation should be allowed to undergo radiosurgery by Gamma Knife, rather than LINAC, if that is the choice of the patient or recommendation by the treating physician. Based on the literature to date, most Canadian patients and many referring physicians have chosen the Gamma Knife as the preferred method of stereotactic radiosurgery. Indeed, approximately 100 patients, mostly with acoustic neuromas, have traveled to other countries, mainly the United States and Sweden, for Gamma Knife treatment. As noted above, the lack of published results about acoustic neuroma from the LINAC groups in Canada has made it difficult to evaluate their results. While fractionated radiosurgical treatment may eventually be shown to be equivalent or superior to Gamma Knife radiosurgery, this technology must also be considered in its early stages and, as stated above, there is considerable variation in methodology and devices among LINAC centers. Unfortunately, it is unlikely that a direct comparison of LINAC versus Gamma Knife stereotactic radiosurgery by a prospective randomized control trial will ever be made. The referring physician in Canada who recommends stereotactic radiosurgery is therefore faced with a dilemma. $\mathrm{He} / \mathrm{she}$ can either recommend to the patient with an acoustic tumor a proven treatment that has been delivered to thousands of patients with this condition worldwide, or one that has been used on a much smaller number of patients with a much shorter follow up time. If LINAC is chosen, there is no problem of access or reimbursement; but if the Gamma Knife is chosen, the patient, and by extension, his/her Canadian physician, usually face a formidable battle to obtain reimbursement for the patient. To date, patients in the provinces of British Columbia, Alberta and Ontario have received reimbursement for Gamma Knife radiosurgical treatment for acoustic neuromas rendered outside of Canada. An appeal in the Province of Manitoba was also recently successful. These decisions have been influenced by the result of a judicial hearing held in Ontario (OHIP v. Arnold, unreported. Ontario Divisional Court, Dec.6, 1993). A court case in the province of Quebec, however, was unsuccessful in obtaining reimbursement for this treatment for a resident of that province. In Ontario, recently, the provincial health insurance agency has chosen to challenge the previous court decision and is no longer funding out-of-country radiosurgical treatment. However, once again, the disadvantaged patients are challenging the decision in the courts. In addition, there is an ethical issue in some provinces in that governments are directing patients to certain physicians and institutions for LINAC treatment and usurping the physicians' role in prescribing treatment.

\section{Conclusions}

The literature to date indicates that the Gamma Knife is a proven, effective treatment for acoustic neuroma in terms of tumor control and acceptable complication rates. While radiation delivered by LINAC seems to be effective in the short term with respect to tumor control and radiation induced morbidity, the volume of patients treated and the published literature worldwide indicate that the LINAC cannot be considered an equivalent technology. Until a unit is available in Canada, it seems likely that the government health insurance agencies will continue to direct physicians to refer their patients with acoustic neuromas, and other "radiosurgical" lesions, to LINAC radiosurgical or fractionated radiotherapy units within Canada. In our opinion, the provincial Ministries of Health should either pay for Gamma Knife treatments in other countries or develop at least one Canadian Gamma Knife facility, until such time as the LINAC is proven to provide an equivalent result. Attempts to prove equivalency will probably take another 7-10 years in view of the very slow growth rate of acoustic neuromas, and the slow evolution of radiation damage to the nervous system.

\section{REFERENCES}

1. Leksell $\mathbf{L}$. The stereotactic method and radiosurgery of the brain. Acta Chir Scand 1951; 102: 316-319.

2. Leksell L. A note on the treatment of acoustic tumors. Acta Chir Scand 1971; 137: 763-765.

3. Laperriere NJ, Bernstein M. Stereotactic radiosurgery. Can J Neurol Sci 1997; 24: 93-94.

4. Verhey LH, Smith V, Serago CF. Comparison of radiosurgery treatment modalities based on physical dose distributions. Int J Radiat Oncol Biol Phys 1998; 40: 497-505.

5. Noren G, Arndt J, Hindmarsh T. Stereotactic radiosurgery in cases of an acoustic neuroma: further experiences. Neurosurgery 1983; 13: 12-22.

6. Noren G, Greitz D, Hirsch A, Lax I. Gamma knife surgery in acoustic tumors. Acta Neurochir Suppl Wien 1993; 58: 104-107.

7. Noren G. Gamma knife radiosurgery for acoustic neuromas. In: Gildenberg PL, Tasker RR, eds. Textbook of Stereotactic and Functional Neurosurgery. New York: McGraw Hill, 1998: 835844.

8. Pollock BE, Lunsford LD, Kondziolka D, Flickinger JC, Bissonette DJ, et al. Outcome analysis of acoustic neuroma management: comparison of microsurgery and stereotactic radiosurgery. Neurosurgery $1995 ; 36: 215-229$.

9. Kondziolka D, Lunsford LD, Flickinger JC. Stereotactic radiosurgery for acoustic tumors: technique and results. Tech Neurosurg 1997; 3: 154-161.

10. Foote RL, Coffey RJ, Swanson JW, Harner SG, Beatty CW, et al. Stereotactic radiosurgery using the gamma knife for acoustic neuromas. Int J Radiat Oncol Biol Phys 1995; 32: 1152-1160. 
11. Flickinger JC, Kondziolka D, Pollock BE, Lunsford LD. Evolution in technique for vestibular schwannoma radiosurgery and effect on outcome. Int J Radiat Oncol Biol Phys 1996; 36: 275-280.

12. Mendenhall WM, Friedman WA, Buatti JM, Bova FJ. Preliminary results of linear accelerator radiosurgery for acoustic schwannomas. J Neurosurg 1996; 85: 1013-1019.

13. Mendenhall WM, Friedman WA, Bova FJ. Linear accelerator-based stereotactic radiosurgery for acoustic schwannomas. Int J Radiat Oncol Biol Phys 1994; 28 803-810.

14. Valentino V, Raimondi AJ. Tumor response and morphological changes of acoustic neuromas after radiosurgery. Acta Neurochir Wien 1995; 133: 157-163.

15. Andrews DW, Silverman CL, Glass J, et al. Preservation of cranial nerve function after treatment of acoustic neuronomas with fractionated stereotactic radiotherapy. preliminary observations in 26 patients. Stereotact Funct Neurosurg 1995; 64: 165-182.
16. Varlotto JM, Schrieve DC, Alexander E 3rd, et al. Fractionated stereotactic radiotherapy for the treatment of acoustic neuromas: preliminary results. Int J Radiat Oncol Biol Phys 1996; 36: 141145.

17. Clark BG, Souhami L, Pla C, et al. The integral biologically effective dose to predict brain stem toxicity of hypofractionated stereotactic radiotherapy. Int J Radiat Oncol Biol Phys 1998; 40: 667.675

18. Schwartz M. Stereotactic radiosurgery: comparing different technologies. Can Med Assoc J 1998; 158: 625-628.

19. Young C, Summerfield R, Schwartz M, O'Brien P, Ramani R. Radiosurgery for arteriovenous malformations: the University of Toronto Experience. Can J Neurol Sci 1997; 24: 99-105.

20. Schwartz ML, Young C, O'Brien P, Ramaini R. Radiosurgery for acoustic neuromas: the Toronto experience. Can J Neurol Sci 1994; 21(Suppl 2): S15-S16. 